\title{
Demographic Change across the Globe Maintaining Social Security in Ageing Economies
}

Marga Peeters and Loek Groot

\section{EERI Research Paper Series No 18/2011}

ISSN: 2031-4892

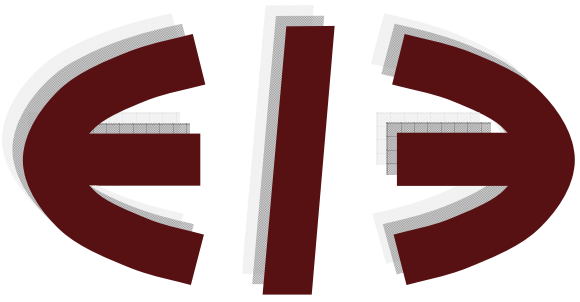

EERI

Economics and Econometrics Research Institute Avenue de Beaulieu

1160 Brussels

Belgium

Tel: +3222988491

Fax: +322 2988490

www.eeri.eu 


\title{
DEMOGRAPHIC CHANGE ACROSS THE GLOBE
}

\section{Maintaining social security in ageing economies}

\author{
Marga Peeters and Loek Groot ${ }^{1}$
}

November 2011

\begin{abstract}
This paper investigates the fiscal pressure from demographic change in relation to the labour market space for fifty countries that cover $75 \%$ of the world population. The pressure-to-space indicator ranks Poland, Turkey and Greece high. Apart from Turkey and India, developing countries rank low due to low spending on the old (pensions, health care) and the young (education, family costs). Peculiarly, economies with higher pressure have more space. The hypothesis that ageing economies have started using their space in anticipation to higher demographic pressure is rejected. Raising the retirement age in developed economies by five years alleviates the pressure by almost $30 \%$ and creates $10 \%$ more labour market space.
\end{abstract}

Keywords: demography, dependency rates, labour market, social security, pensions, government spending.

JEL codes: D6, E24, E62, H51, H52, H53, H55, J0, J11, J18, J21, J26, 057.

\footnotetext{
1 Correspondence addresses: huber@TinaMargaPeeters.eu and L.F.M.Groot@uu.nl. Marga Peeters is fellow-in-residence at the Netherlands Institute for Advanced Study (NIAS) of the Royal Netherlands Academy of Arts and Sciences (KNAW) in Wassenaar and Loek Groot is associate professor at the Utrecht University School of Economics. We are grateful for financial support from the NIAS and thank Bas van Groezen and participants from both institutions for helpful comments.
} 


\section{INTRODUCTION}

Fiscal pressure from ageing is mounting in developed but also developing economies. As the population share of the workforce shrinks, workers are burdened with higher fiscal costs (pensions, health care, education, family costs). This paper relatespublic expenditure on the dependent people in an economy to the labour market situation,in view of the changing demographic structure. A key variable in our analyses is labour market space, defined as the directly available room in the labour market of people that are of working age but not working (full time). Fiscal pressure can be alleviated by using labour market space more optimally.

The process of projecting demographic change, although still an inexact science, depends only on a few key parameters (fertility, life expectancy and migration, see e.g. Bloom et al.2010:10). In our analysis, we use UN projections up to the year 2100 and relate them to current labour market information. Our analysis covers fifty main countries, split into developed and developing countries, according to their GDP per capita. We cover $75 \%$ of the world population. The data set is described in more detail in Groot and Peeters (2011).

The aim of this paper is to investigate to what extent and when the sustainability of social security is at risk due to demographic change, in relation to labour market space. Recently, a large number of studies have focussed on the demographic challenge of ageing, but without paying explicit attention to the role of the unused potential at the labour market, which we label as labour market space, to cope with this challenge (see e.g. Andersen (1990), Hagist and Raffelhü schen (2011) a mong ot hers) Mbre space gi ves roo mt o manoeuvre The d sti nction between developing and developed economies is crucial here. Developed economies are ageing more rapidly than developing economies. Moreover, they incur far higher family, education, health and pensioncost per capita. We study both groups of countries and run scenario analyses to analyse the impact of increases in health and pensioncosts (for the developing economies) as well as a higher retirement age.

The outline of this paper is as follows. Section 2 specifies labour market space,demographic pressure andthe indicator pressure-to-space thatis usedlater on to rank countries. Section 3 illustratesthe main statistics, such as dependency ratios, pressure andlabour market space for the two groups of developing and developed economies. It also presents the ranking according to pressure-to-space across countries for several decades. Section 4 tests econometrically the correlation between pressure and space in a cross-section analysis, as well as the causality from pressure to space in a panel regression. Section 5 shows the results of the scenario analyses. Section 6 summarizes, concludes on policy issues and suggestsavenues for future research. 


\section{THE PRESSURE-TO-SPACE INDICATOR}

The indicator for demographic-pressure-to-labour-market-spacespecifies the fiscal pressure mounting from the dependant part of the population in relation to non-working share of the working age population (see also Groot and Peeters (2011)). For country $i$ at time $t$ it is defined as

$$
\operatorname{PtS}_{i, t}:=\frac{\text { ypres }_{i, t}+\text { opres }_{i, t}}{\text { space }_{i, t}}
$$

withypresand opresthe fiscal costs of the young and the old population, respectively,and space the labour market space.

As illustrated in Figure 1, we split thepopulation of each nation into three categories: young people (YAP) defined as those below 15 years, old people as those above $65(O A P)$, and the working age population (WAP) as those between 15 and 65 years. The labour market space is the share of the working age populationthat is not workingmeasured in full-time equivalents.According to this definition, people enter the labour market at 15 and leave it at 65, an assumption that we will loosen afterwards (see section 5).

Figure 1 Categorised population pyramid

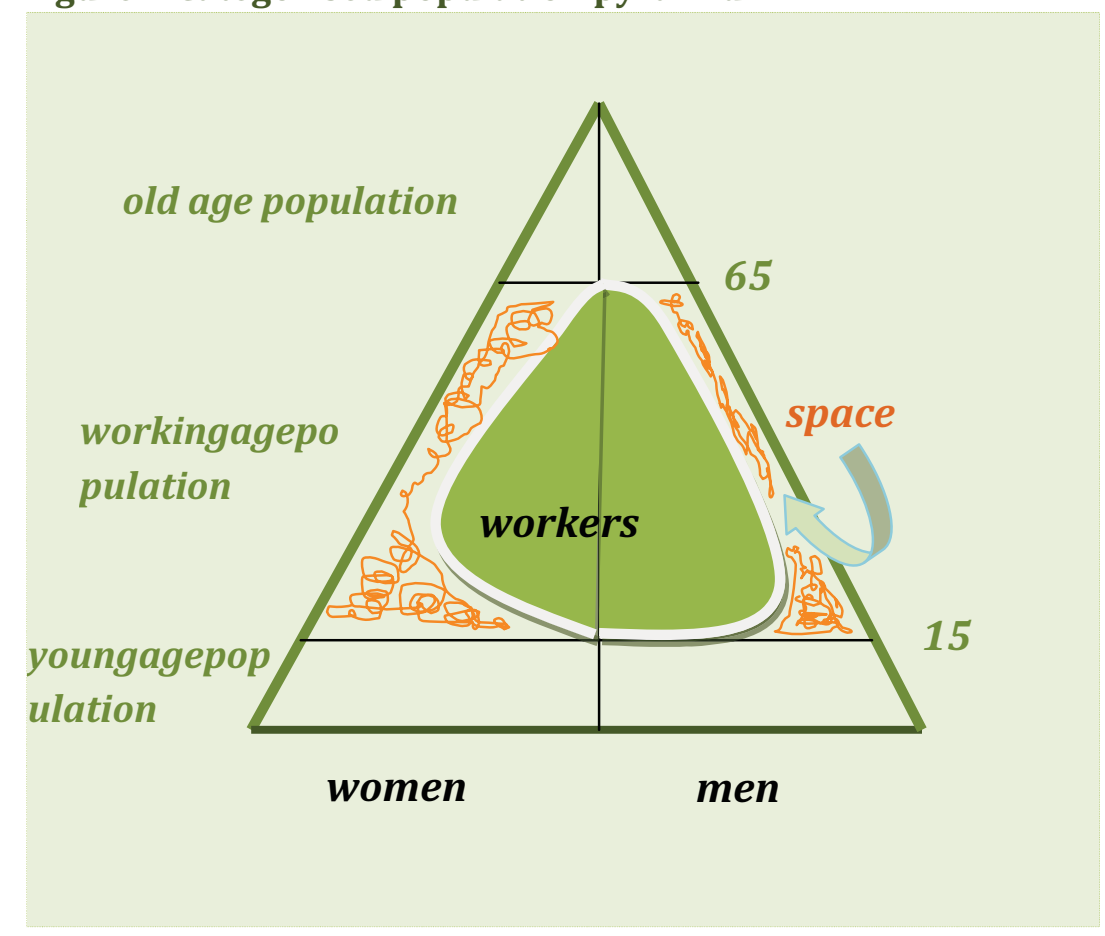

Source: Authors. 
Note:A population is divided into the young (yap), old (oap) and working-age people (wap), where the latter is divided into workers measured in full-time equivalents and those in the space (s).The surface of the triangle is set to unity, so that yap + wap + oap $=1$.

The number of young and old people, relative to the working part of the labour force, and the average government spending per old and young person defines the fiscal pressure. The total fiscal costs thus have a volume and price effect. Denoting the nominal fiscal spending for each young person as $Y G$ and for each old person as $O G$, it follows that the twoterms in the nominator in equation (1)are specified as

$$
\operatorname{ypres}_{i, t}:=\frac{Y A P_{i, t} * Y G_{i, t}}{G D P_{i, t}}
$$

and

$$
\text { opres }_{i, t}:=\frac{O A P_{i, t} * O G_{i, t}}{G D P_{i, t}}
$$

with YAP and $O A P$ the number of young and old persons and GDP the nominal gross domestic product. Fiscal costs on young people consist of family costs and education. Fiscal costs for old people consist of state pensions and health care costs.

The labour market space, the denominator of equation (1), depends on the employment rate and the average number of hours per worker. It can be defined as the complement of the employment rate (er) weighted by the average number of working hours $(H)$ of the employed relative to full-time maximum working hours $\left(H_{\max }\right)$

$$
\text { space }_{i, t}:=1-e r_{i, t} \frac{H_{i, t}}{H_{\max }}
$$

With the employment rateequal to the ratio of the number of employed persons $(E)$ and the working age population (WAP)

$$
e r_{i, t}:=\frac{E_{i, t}}{W A P_{i, t}}
$$

In our empirical analysis - see next section - we set the maximum number of hours worked equal to $2080(=52 * 40)$ hours per year for the developed economies. Due to lack of dataon 
working hours for the developing economies, the ratio of hours to the maximum number of hours is set equal to 1 and thus only the employment rate determines space.

Each person between the age of 15 and 65 is part of the working-age population. The employment rate incorporates the effect of early retirement since the closer the effective retirement age is to the age of 65 , the higher the number of employed in the nominator of equation(4).Note that unemployed and non-working disabled persons are part of the space.

Some countries already face a high pressure-to-space and seem to cope with it, probably because the fiscal costs (high pressure) are shouldered by many workers (low space). More salient arethe economies that face a major change in pressure for the years to come. To alleviate the pressure and to cover additional fiscal costs resulting from demographic change, they can try to increase the labour market participation by implementing labour market reforms. Labour market reforms is typically a process of piecemeal social engineering and takes considerable implementation time. Even after the implementation of reforms, it takes time before the general equilibrium effects have become fully effective.Thus, the pressure variables at some future year $T$ will be compared with the space variable at time $t$ (today) in our empirical analyses, where $T-t$ equals one, two up to ninedecades. Using equation (1) we measure the change in the pressure at time $T$ in comparison with the pressure and space in period $t$ as

$$
\Delta_{T-t} \text { PtS }_{i}:=\frac{\Delta_{T-t} \text { ypres }_{i}+\Delta_{T-t} \text { opres }_{i}}{\text { space }_{i}}
$$

with $\Delta_{T-t}$ xpres $_{i}:=\operatorname{xpres}_{i, T}-\operatorname{xpres}_{i, t}(x=y, o)$.

We keep the cost of young peopleand old peoplerelative to GDP per capita (productivity), denoted by $\varphi_{i}$, and $\theta_{i}$ respectively, constant over time but country specific, so

$$
\Delta_{T-t} \text { ypres }_{i}=\varphi_{i} * \Delta_{T-t} \text { yap }_{i} \Delta_{T-t} \text { opres }_{i}=\theta_{i} * \Delta_{T-t} \text { oap }_{i}
$$

with yap the share of the young and oapthe share of the old in the total population (see also Volker and Werding (2010)). By assuming constant, but country specific, generosity towards the young and old over time, the pressure variables reflect the changingfiscal burdens entirely due to changes in the age structure of the population. 


\section{EMPIRICAL ANALYSES}

Our empirical analyses concentrate on the main economies in terms of GDP and population worldwide. We include 50 economies, of which 21 are developing and 29 aredeveloped, where the first are defined as countries with an average GDP per capita of less than 12,000 euro in $2010 .^{2}$ According to our calculations based on UN projections, the population in 2050 for these 50 countries will be 7.0 billion, being $75 \%$ of the 9.3 billion projected for the whole world. The coverage for 2010 is 79\%: 5.4 of the 6.9 billion.Figures 2 to 7 illustrate basic statistics for the group of developing and developed economies, where the line represents the median and the area represents the range between the lowest and the highest value across the countries ineach group per year. We treat each country as a separate case (sui generis) and the (unweighted) median thus informs us about the position of the median country in each group.

Figure 2 shows that the median population share of the working-age population (wap) in developing economies has been increasing sharply, from 54\% in 1970 to more than $65 \%$ in 2010. For the decades to come, the expectation is that the wapgradually falls as fertility rates slightly drop and the population is ageing. In the median developed economythe declineof the waphad alreadybegunin 2000 and continues to fallup to 2100 .

Figure 3a-3c show the young and old age dependency ratesfor the period 1950-2100. For both the developing and the developed economies, the median value of the young age dependency rate declines sharply (Figure 3a), whilefor the old age dependency rateit rises strongly (3b). The developed economies already reach an old age dependency rate of $45 \%$ in 2050 . This is relevant for our study on fiscal sustainability as old people are more costly than young people, in terms of state pensions and health care. While the developed economies age rapidly from 5.9 working age persons per old person in 1970 to 2.4 in 2050, the developing economies move from 15.3 in 1970 to 4.6 in 2050. Ageing thus also takes place in the latter group, but it starts from a different level. The turn in the median of the total (young and old age)dependency ratealready took place in 2000 in the developed economies, while for the developing economies it

\footnotetext{
2 Developing countries included are Argentina, Bangladesh, Bulgaria, Brazil, China, the Democratic Republic of Congo, Egypt, Ethiopia, India, Indonesia, Kenya, Mexico, Nigeria, Pakistan, Philippines, Romania, Russia, South Africa, Turkey, Tanzania and Uganda. Developed countries included are Australia, Austria, Belgium, Canada, the Czech Republic, Denmark, Finland, France, Germany, Great Britain, Greece, Hungary, Iceland, Ireland, Italy, Japan, South Korea, Luxembourg, the Netherlands, Norway, New Zealand, Poland, Portugal, Saudi Arabia, Slovakia, Spain, Sweden, Switzerland and the United States of America.
} 
Figure2Working age population as a percentage of the total population, $100 * \frac{W A P}{P O P}$

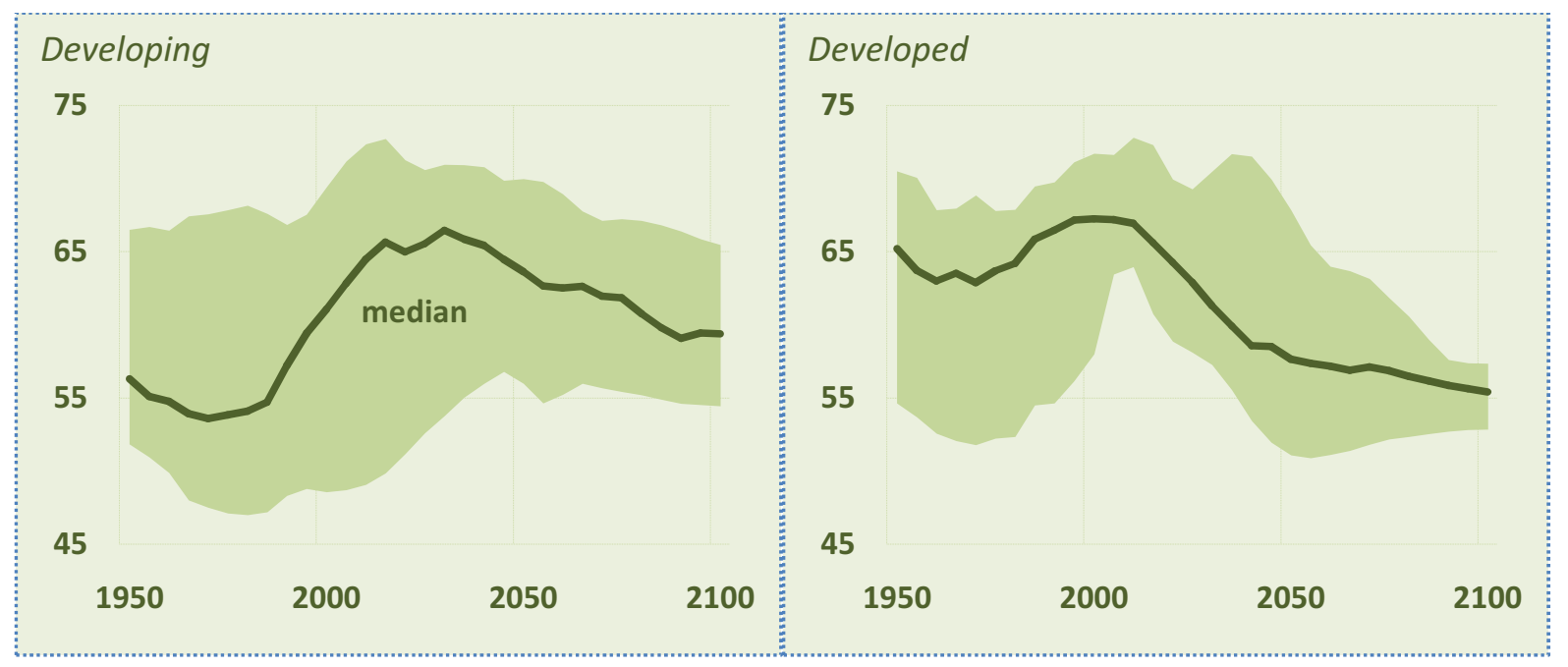

Source: Own calculations based on United Nations Population Information Network 2011.

will not happen before 2040 (Figure 3c). The graph further shows that while in the past the combined dependency rate was much higher in the developing countries, for the future it is the other way around (for the median developed country, it is expected to increase from 48.7 in 2000 to 73.4 in 2050).

To summarize,even under the assumption thatrelative costs on pensions, health care, family and education will remain constant in time, the fiscal burden increases due to the growing numbers of old and young relative to those of working age. The available space in the labour market thus becomes more important, as this space can be utilised to alleviate pressure.

As Figure 4 shows, the median value for space in the developing economies has hovered around $30 \%$ in the period 1990-2008. We have to recall here that due to lack of data we assumedthat each working person in a developing economy has a full-timejob,while we tookinformation about average workinghours per worker into account for the developed economies. In developed economies, part-time work, temporary leave (maternity, parental), longer educational careers and welfare programs have contributed to a considerable share of the workforce not doing paid work. Labour market space in developed economies is on average hovering around $40 \%$ in the period $1970-2010$ and the median value is rather constant, although there is considerable variation across countries. 
Figure 3aYoung age dependency rates, $100 * \frac{Y A P}{W A P}$

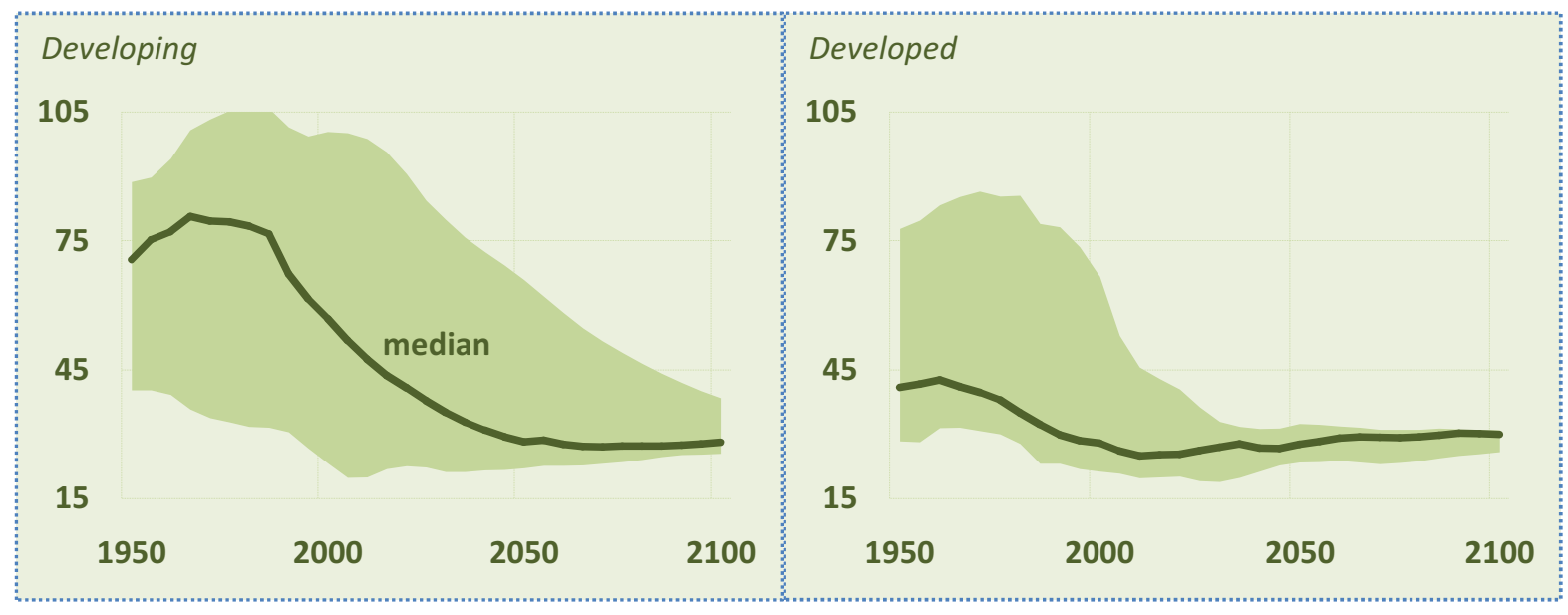

Figure 3b0ld age dependency rates, $100 * \frac{O A P}{W A P}$

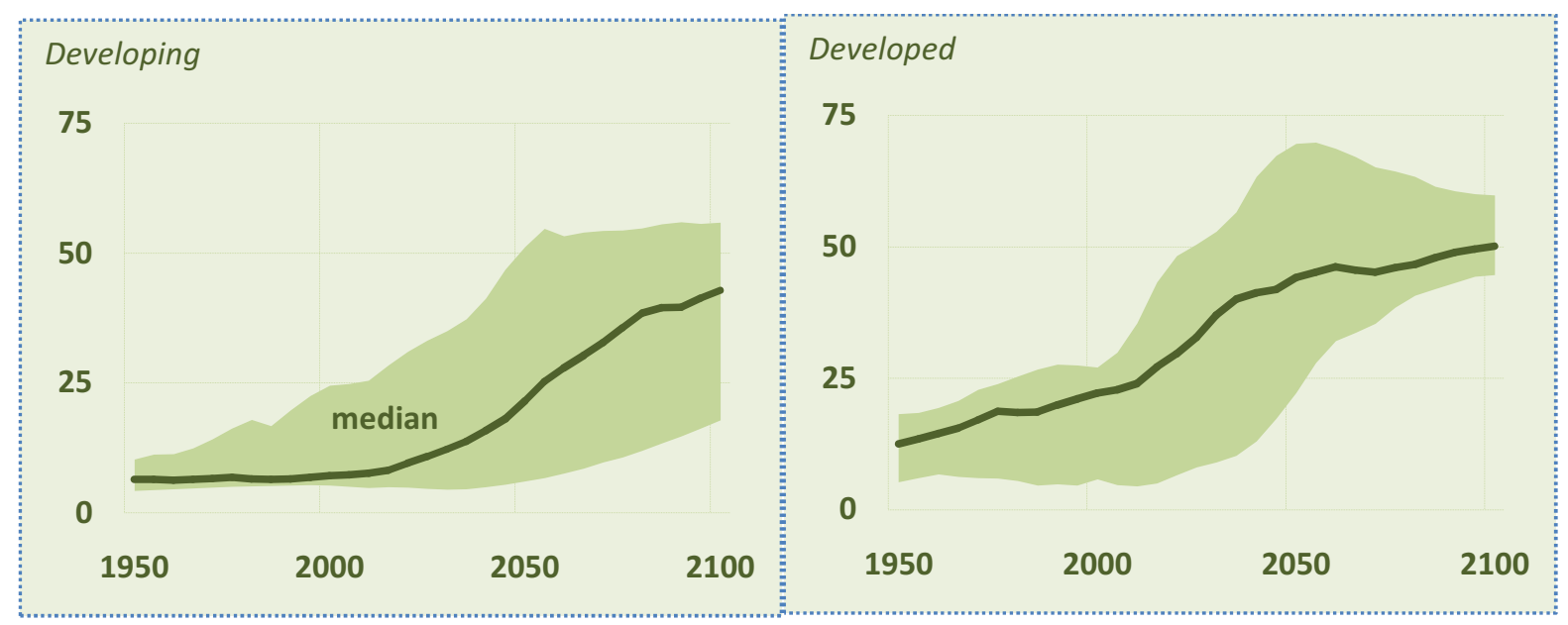

Figure 3cYoung and old age dependency rates, $100 * \frac{Y A P+O A P}{W A P}$

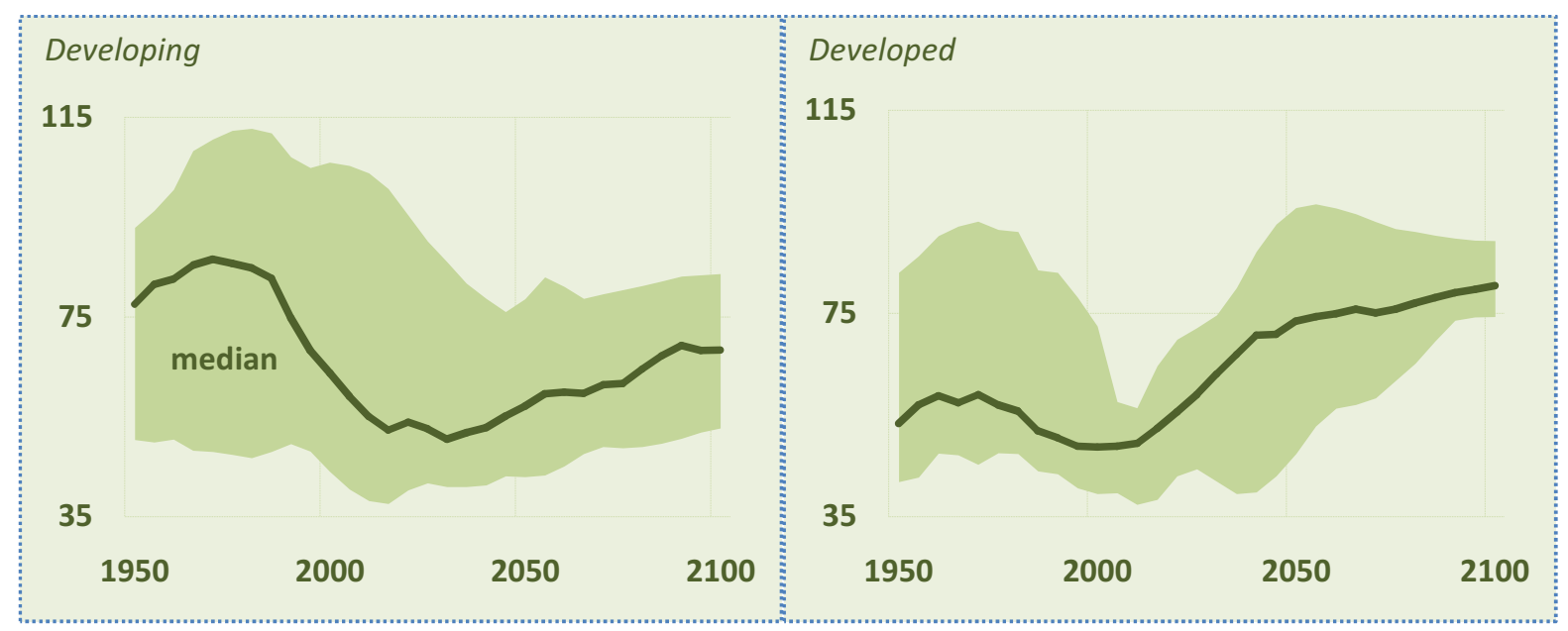

Source: Own calculations based on United Nations Population Information Network 2011. Note: See figures 2, 3 and 4. 
Figure 4Labour market space, $100 *$ space

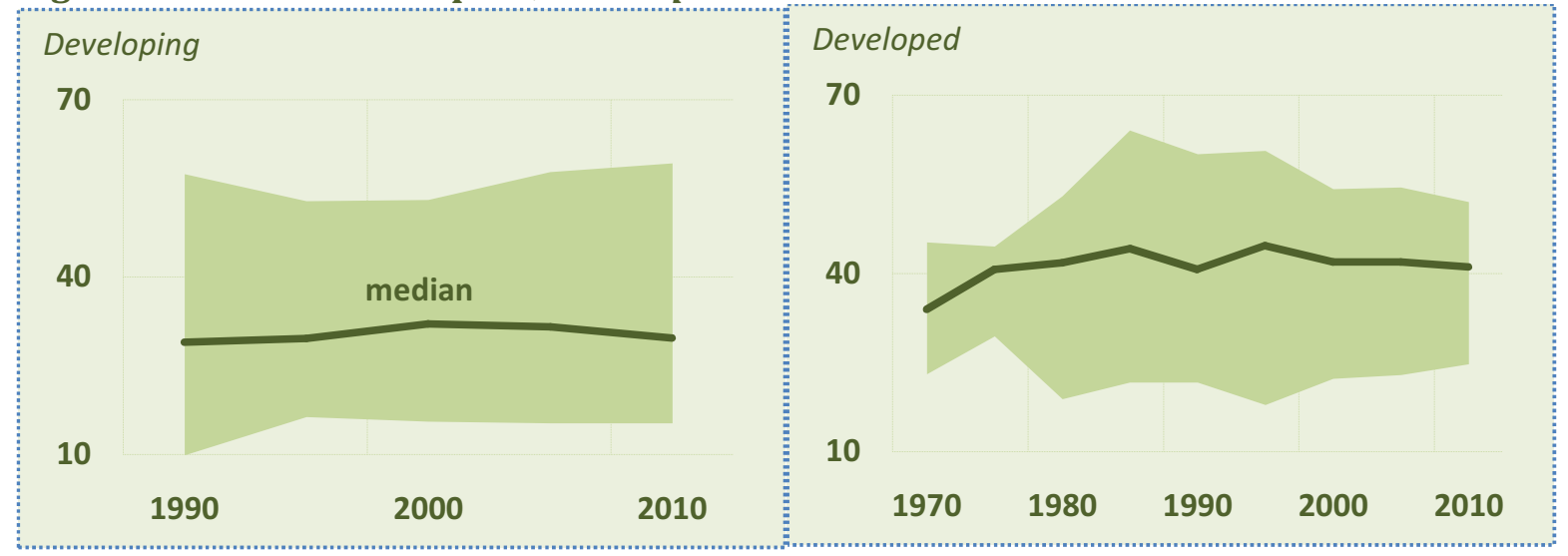

Source: Authors' calculations according to equation (3).

Figure 5Inactive-to-active ratio, $100 * \frac{\mathrm{YAP}+0 \mathrm{AP}+\mathrm{s} * \mathrm{WAP}}{(1-\text { space }) * \mathrm{WAP}}$

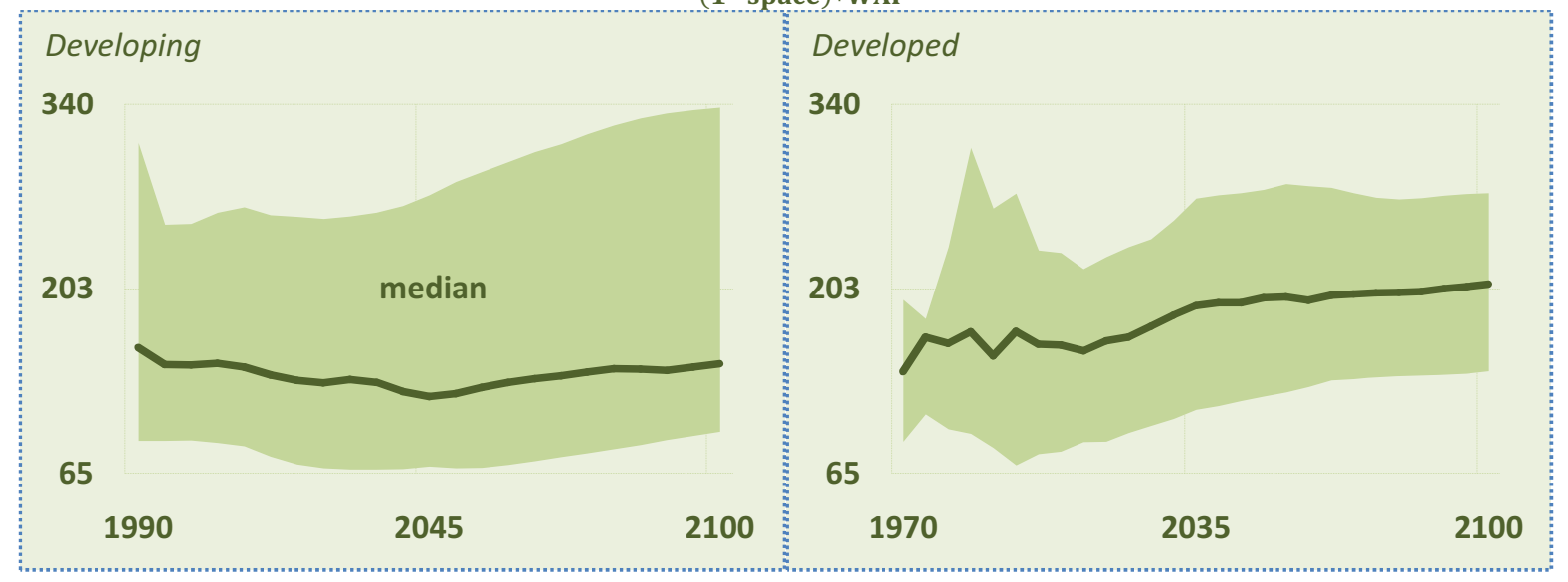

Note: The space from 2010 onwards is kept constant.

Figure 6 Pressure-to-space of the old and the young

in percentage points of GDP related to the space in 2008

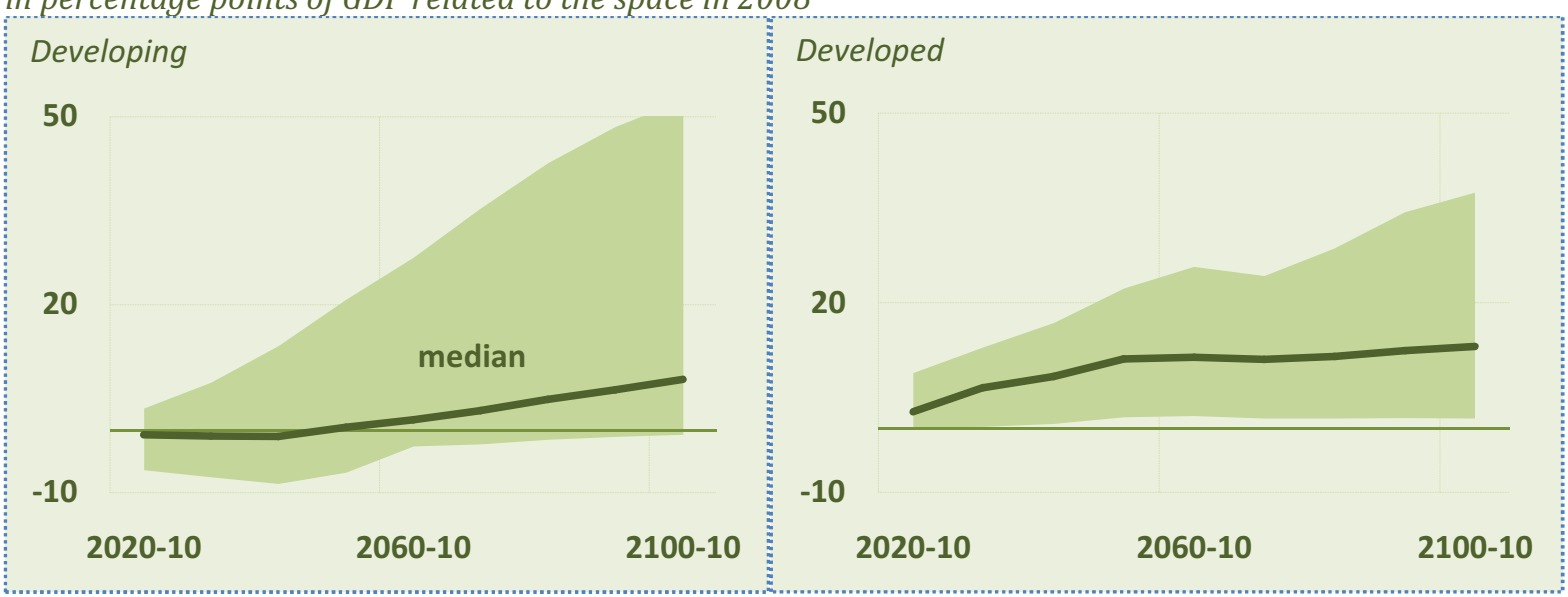

Source: Authors' calculations based on UN POPIN and the OECD.

Note: Equation (5) for 2020 in comparison with 2008, denoted as 2020-08, as also for 2030, 2040 and 2050 in comparison with 2008. 
Figure 5 shows the ratio of inactive to active personsup to 2100, where we keep the space constant after 2010. Theseratios are more than twice as high as the young and old age dependency rates, which justifies the inclusion of space in the analysis. For the median in the developed countries, after 2035 against every full-time worker there are two persons inactive.

Now that we have shown pressure and space, we arrive at the focal point of our analysis, being the pressure-to-space (Figure 6). Due to lack of information on fiscal spending for most developing economieswe were forced to make some bold assumptions. We assumed the fiscal spending to GDP per capita to be equal to the lowest level among the set of developing countries for which we have reliable information, being OECD-member Mexico (see section 4 for sensitivity analyses on this assumption). Since our focus is on the change in pressure (see equation (5),we measure deviations from the base level in 2008(space is in all cases measured in 2008 , our latest realistic figures, as this is the year just before the global recession year) for each decade starting in 2020.

Figure 6 pictures the change in pressure-to-space over time. For the developing countries,the median value onlybecomes positive after 2050.There are however developing countries in which the fiscal pressure rises $40 \%$ points in this period, in comparison to the space, as the range shows (Turkey). The picture ismore gloomy for the developed economies. The change in pressure-to-space is positive over the full range. Since we assumed space constant after 2008, this implies rising fiscal costs over the decades to come in comparison with 2008, ceteris paribus.

Figure 7 disaggregatesthe results for 2020-08 as shown in Figure 6 and presents thesetof all countries with pressure on the horizontal axisand spaceon the vertical axis. Interestingly, developed countries belonging to the same welfare regimetype cluster together (see EspingAndersen (1990)and Van der Veen and Groot (2006) for a classification of countries).Most interestingfor our analyses are the countries at the right side. Here you find the countries with the highest change in pressure such as Japan, the Czech Republic and Poland, but varying in the amount of space. 
Figure 7Demographic pressure of the young andold versus labour market space pressure in \%-points of GDP and space in \%

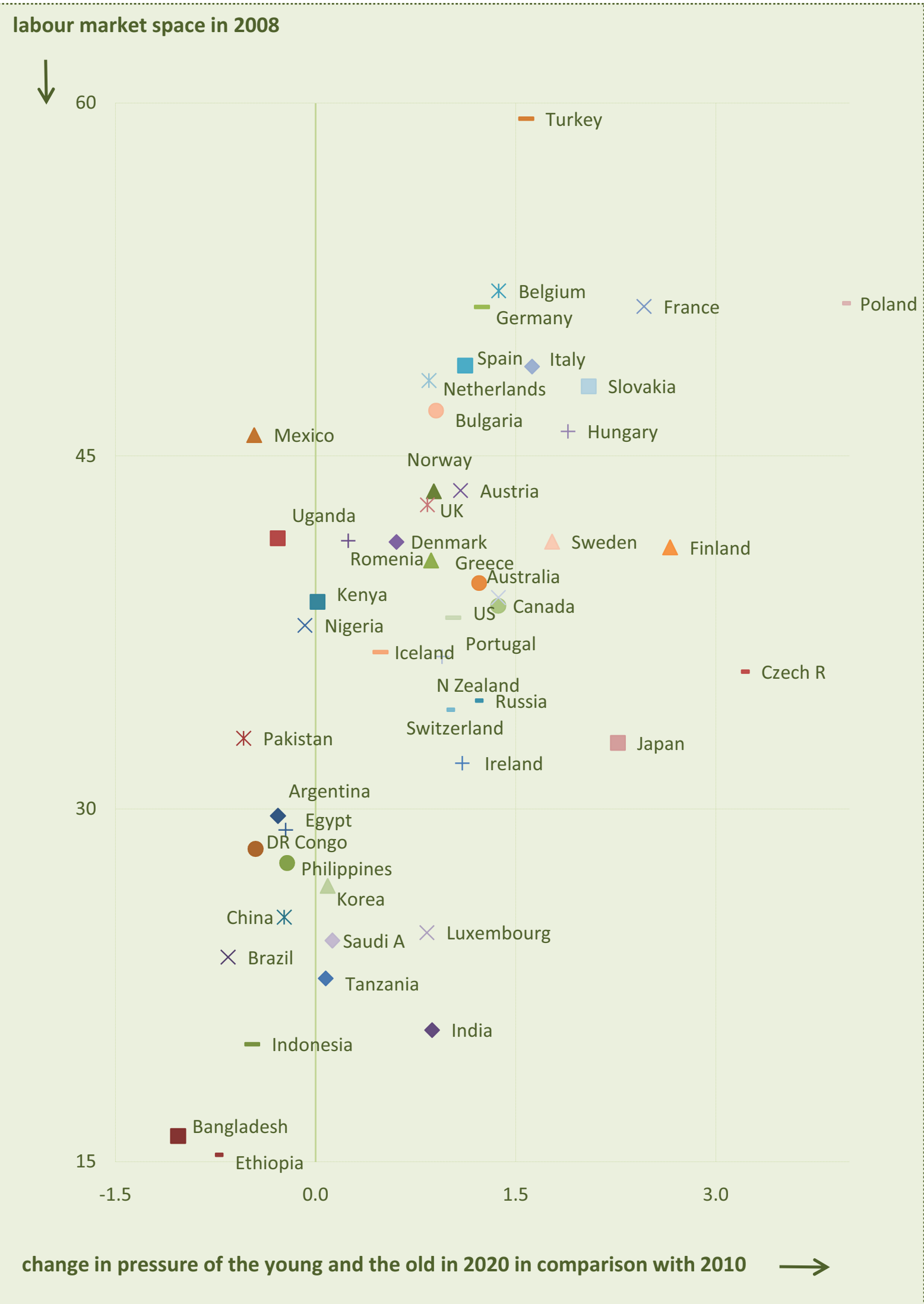

Source: Authors' calculations. 
From 2008 to 2020, Poland faces an increase in fiscal pressure of almost 4\%. In contrast, the demographic dynamics in all developing economies except India are expected to lead to no extra or even todecreasing fiscal costs. The wide variety in fiscal pressure, from $-1.5 \%$ to $4.0 \%$ together with the huge variety in labour space, ranging from 15 to $60 \%$, underlines the diversity of the economies in fiscal and labour market aspects. This scatter plot suggests a positive correlation. If this relation is indeed significant, itis good news as economies facing increasing pressure currently have more labour market space as well, and the lattercan be usedto alleviate rising fiscal costs per capita (see also the next section).

In order to see the evolution over time, Table 1 shows the change in the pressure-tospaceindicator for each decade from 2020 to 2100 . Note that since we assumed both space and relative expenditures to young and old constant, the change in pressure-to-space is entirely driven by demographic changes (see equation (6)). We categorised the rate of change in the indicator intohigh (dark red), medium (light red) and no or low change (green). For instance, the Czech Republic ranks highest as their fiscal expenditures are expected to growstrongly in comparison with 2008 and their labour market space is relatively low. Japanscores red until 2050, but afterwards the change in pressure-to-space compared to the base year is in the medium range. Saudi Arabia moves in the opposite direction.

In the countries where pressure is increasing in the near future policy makers might feel a sense of urgency to adapt either government spending or labour market policies to accommodate additional costs. In section 4 we statistically test whether the change in pressure in the near future is somehow related to the level of labour market space now. As said, Figure 7 suggests a positive correlation between change in pressure and space. 
Table 1 Rankings of the changes in pressure-to-space of the young and the old

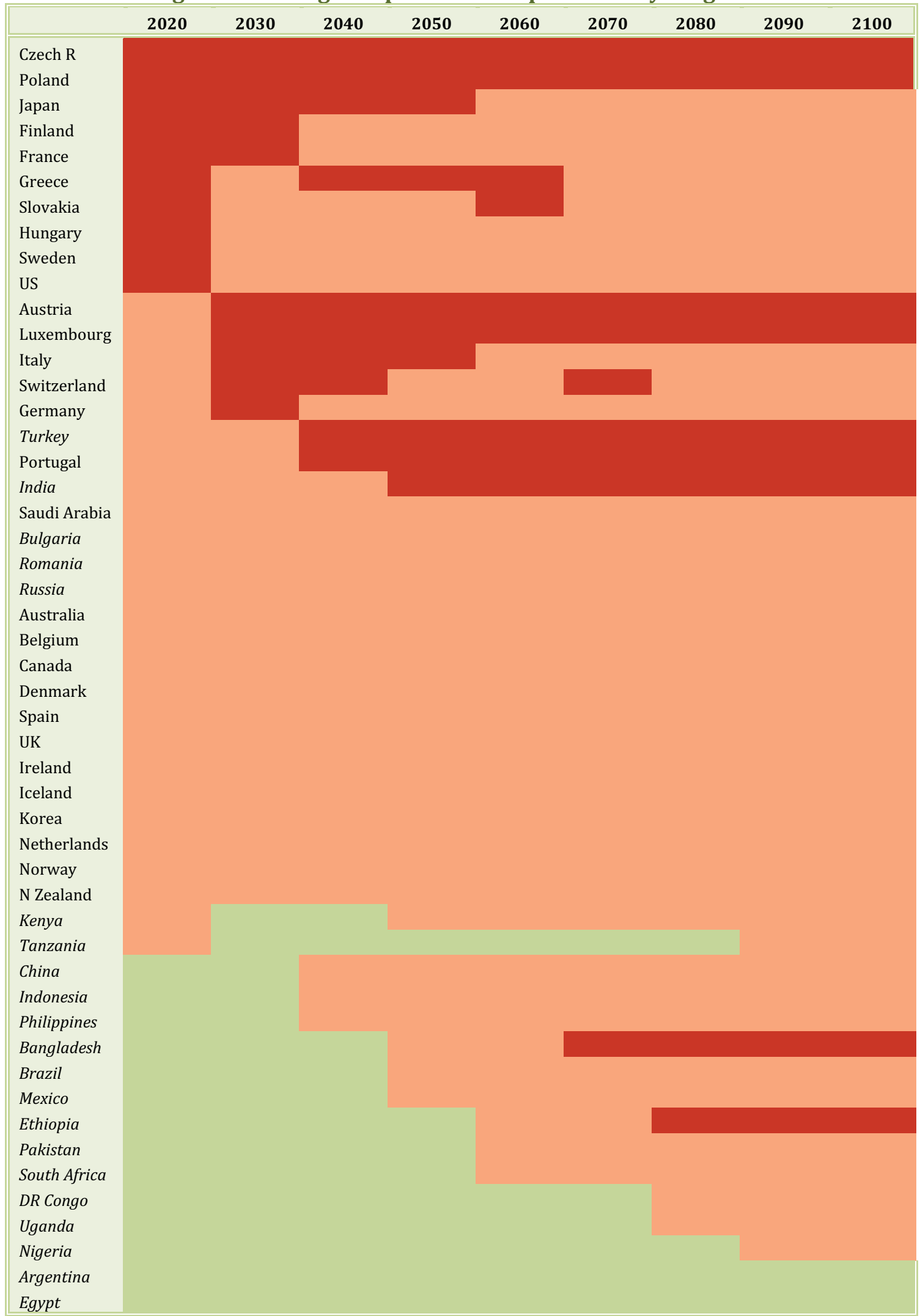

Note: Authors' calculations according to equation (5).Nohealth care costsare included. Developing economies are in italic. Dark red indicates that the country ranks in the top 10 of the year. Light green indicates that the fiscal pressure decreases in comparison with 2008. Red is the case in between. 


\section{CROSS SECTION AND PANEL CAUSALITY TESTS ON PRESSURE AND SPACE}

So far we have mainly focussed on the median country among the set of developing and developed countries. However, we also saw that there is considerable variation among countries. Now we want to make use of this variation to see if there is any relationship between labour market space in 2008 and the change in pressure from 2010 to 2020 (see Figure 7). Running a univariate ordinary least squares (OLS) regression, splitting the pressure exerted by the young and the old, gives

$$
\text { space }_{i, 2008}=0.33+0.07 * \Delta_{2020-10} \text { ypres }_{i}+0.05 * \Delta_{2020-10} \text { opres }_{i}
$$

$(15.5)(2.59)(3.44)$

with the countries denoted by subscript $\mathrm{i}=1,2 \ldots 50$ and an adjusted goodness-of-fit $R_{\text {adj }}^{2}=0.32$. According to the $t$-values shown in brackets, both the change in pressure of the young and the pressure of the old is highly significant and positively correlated with the level of labour market space. The reaction coefficient of the pressure of the young is 0.07 and of the old 0.05 . This implies that acountry with a 1\%-point higher change in pressure of the young as a percentage of GDP in comparison with another country has a larger space of $7 \%$. A country with a $1 \%$-point higher change in pressure of the old has a $5 \%$ larger space than its peers.

This static analysis thus indicates that in our sample of 50 countries, the morethat pressure risesbetween 2010 and 2020, the higher the level of space will be. This is good news. Pressurized economies can use this greater amount of space to adjust their labour markets in order to keep the fiscal costs under control.

One may wonder whether or notcountries are forward looking in their policies and that present and past measures have been takenin view ofdemographic changes anticipated in the near future. As a solution at hand, highly-pressurized countries might increase labour market participation by stimulating more people to work full-timeinstead of part-time, inserting more of the unemployed in the working labour force or to discourage early retirement. In all these situations, the labour market space narrows.The mounting fiscal pressure exerted by the dependent population in the near future is thencausing space to be lower. 


\begin{tabular}{|c|c|c|c|}
\hline & All countries & Developing & Developed \\
\hline \multirow[t]{2}{*}{ ypres $_{i, t+10}-$ ypres $_{i, t}$} & 0.001 & -0.003 & 0.007 \\
\hline & $(0.20)$ & $(-0.25)$ & $(1.21)$ \\
\hline \multirow[t]{2}{*}{ opres $_{i, t+10}-$ opres $_{i, t}$} & 0.004 & 0.05 & 0.001 \\
\hline & $(0.54)$ & $(1.62)$ & $(0.09)$ \\
\hline \multirow[t]{2}{*}{ constant } & $0.37^{* *}$ & $0.31^{* *}$ & $0.40 * *$ \\
\hline & (53.4) & $(28.5)$ & $(51.8)$ \\
\hline Adjusted $R^{2}$ & 0.96 & 0.94 & 0.96 \\
\hline Fixed country dummies & significant & significant & significant \\
\hline Fixed time dummies & insignificant & insignificant & significant \\
\hline Number of countries & 50 & 21 & 29 \\
\hline Number of observations & 150 & 63 & 87 \\
\hline Sample & $2000-2010$ & $2000-2010$ & $2000-2010$ \\
\hline
\end{tabular}

Source: Authors' calculations.

Note: The dependent variable is space $_{i, t}$. The $t$-values denoted in brackets. One star indicates that the included explanatory variable is significant at the $5 \%$ level.

To test for this dynamic causality, running from pressure to space, we perform an econometric panel analysis. This accounts for the cross-section of 50 countries followed over a number of years. The time series dimension that we use for the space for each country covers 2000-2010 as this is the period for which we have data points for each country. Only each fifth year is included due to the availability of the UN data on demographic developments. Because we take first differences of the future values in the pressure variable, it implies that there are three data points in time: 2000, 2005 and 2010 (2010-00, 2015-05 and 2020-10 for the pressure). The sample is thus balanced as each variable is observed at each point in time.

We run an OLS-regression of the labour market space on the change in young and old age fiscal pressure. The latter is observed at $t+10$ in deviation from $t$, which we denote alike in the subscripts of the explanatory variables. We testedextensively whether random or fixed effects are significant. It turns out that the fixed effects deliver adjusted $R^{2}$ 's of more than $90 \%$, while the random effects only get us to $30 \%$. 
Table 2 reports the estimated results for the full sample, for the group of developing economies and for the group of developed economies. It shows that neither the change in young nor in old age pressure affects the current level of space for the full sample of fifty countries. Splitting the sample into developing and developed economies does not alter the results much. We also experimented with 5-year differences, with past changes in pressure and the levels of pressure, but none of these gave us significant parameter estimates for the pressure variables. We thus conclude that labour market space does not changein anticipation to future (or past) increases inpressure. The outcome that countries facing increasing pressure tend to have more space of the static analysis still holds, but from a dynamic perspective it cannot be concluded that countries expecting an increase in pressure already anticipated by reducing their space. Note that both outcomes are not inconsistent with each other. After all, in case the current space were reduced in reaction to rising fiscal costs in the future,the relationship in the static test were not significantly positive. ${ }^{3}$

\section{SCENARIO ANALYSES}

In our baseline scenario, the median old age pressure is 1.6\% of GDP in 2020 in the developing countries and $7.8 \%$ in the developed economies (Table 3). The range within each groupin 2020 is broad (see Figure 3b), varying from $0.6 \%$ of GDP to $8.2 \%$ of GDP for the developing and from 2.1 to $15.7 \%$ for the developed economies. Of course, our projections are surrounded by greatuncertainty, if only because policy measures will make that actual outcomes deviate from baseline projections. We will focus on two such policies, public health care policyand adjustment of the official retirement age. Public health costs are highly relevant as in ageing societies the demand for health care is expected to rise. Based on anecdotal evidence from developed economies, we assume that the old aged are responsible for a share of $80 \%$ of national health costs. As Table 3 shows,including health care cost meansthat the median old age costs almost double in value. In comparison with the baseline,they increase by 2.5 for the developing and by $6.5 \%$-points of GDP in 2020 for the developed economies.

\footnotetext{
${ }^{3}$ This follows from the pressure-to-space indicator as the denominator falls in case of a reduction in space. High levels of the pressure-to-spaceindicator could therefore also indicate that countries already decreased their space in response to the pressure. But our causality tests here reject this thesis.
} 
In view of the retiring 'babyboomers'and the rising longevity of people in general, many countries have already raised the official retirement age, which broadens the working age populationand reduces the caseload of people dependent on a pension income.Information about public pension costs for developing economies is only scarcely available, so we relied in our baseline scenario on the OECD statistics for Mexico. Weequatedthe public pension costper old age relative to GDP per capita for developing economies with no information on pensionsto the Mexican level, which spent1.4\% of GDPon pensions in 2009. On the one hand, some economies classified as "developing" will face lower public costs because theirelderly, in the absence of public pensions, are taken care of by their relatives.On the other hand, other countries may incur higher costs, especially if future economic growth is used to provide income protection for the elderly. For the scenario analysis, we picked Turkey,the only other OECD member among the developing countries, which spent $6.1 \%$ of GDP in 2008, and take this as our measure for all developing economies. The old age pressure increaseson average with 5.5\%points in 2020 and 11.5\% in 2050 in comparison with the baseline (Table 3). While only Turkey and India figure high in the pressure-to-space ranking (Table 1), higher pension costs for developing economies to this extent will lift more developing economies higher up in our pressure-to-space ranking, surpassing some developed economies. This scenario shows that if public pensions become more prevalent in developing economies, its associated costscan be significant.

Raising the retirement age has two direct effects. First, it broadens the working age population. Second, less money is paid in pensions. To show the impact, we simulate that the working-age population is broadened from people in the range of 15-65 years to those in the range of 15-70 years. Working five years more implies receiving a state pension five years later. The median labour market space in the developing economies increases in this case by $3.4 \%$ of the working population (we assume all in between 65 and 70 years of age are not working) while the median old age pressure decreases 0.6 percentage points in 2020 and 1.1 in 2050, in deviation from the baseline (Table 3). As the developed economies age faster, their working age population increases in $4.2 \%$ full-time equivalents. In this scenario, fiscal pressure is alleviated by more than 2\%-points of GDP in comparison with the baseline. This is no small money, since the pressure from ageing decreases by $27 \%(2.1 / 7.8)$ while the median space increases by $10 \%$ $(4.2 / 41)$. Note that here we even did not take into account the effect that raising the retirement age will have, i.e. to increase the number of workers and thus broaden the tax base. 


\begin{tabular}{|c|c|c|c|}
\hline & & Developing & Developed \\
\hline \multicolumn{4}{|c|}{ Baseline old age pressure - in \% of GDP } \\
\hline \multirow{2}{*}{\multicolumn{2}{|c|}{2020}} & 1.6 & 7.8 \\
\hline & & $(0.6 ; 8.2)$ & $(2.1 ; 15.7)$ \\
\hline \multirow{2}{*}{\multicolumn{2}{|c|}{2050}} & 3.0 & 11.9 \\
\hline & & $(1.2 ; 20.1)$ & $(3.7 ; 22.6)$ \\
\hline \multicolumn{4}{|c|}{ Including health costs - old age pressure in deviation from the baseline, in \%-points } \\
\hline \multirow{2}{*}{\multicolumn{2}{|c|}{2020}} & 2.5 & 6.5 \\
\hline & & $(0.0 ; 5.2)$ & $(4.0 ; 7.2)$ \\
\hline \multirow{2}{*}{\multicolumn{2}{|c|}{2050}} & 4.6 & 8.3 \\
\hline & & $(0.0 ; 10.8)$ & $(9.0 ; 8.5)$ \\
\hline \multicolumn{4}{|c|}{ Higher pension costs for the developing economies - old age pressure in deviation from the baseline, \%-point } \\
\hline \multirow{2}{*}{\multicolumn{2}{|c|}{2020}} & 5.5 & \\
\hline & & $(5.5 ; 0.7)$ & \\
\hline \multirow{2}{*}{\multicolumn{2}{|c|}{2050}} & 11.5 & \\
\hline & & $(7.1 ; 1.2)$ & \\
\hline \multicolumn{4}{|c|}{ Working age population increased by 5 years - space in deviation from the baseline, \%-points } \\
\hline 2008 & & 3.4 & 4.2 \\
\hline \multicolumn{4}{|c|}{ Working age population increased by 5 years - old age pressure in deviation from the baseline,\%-points } \\
\hline \multirow{2}{*}{\multicolumn{2}{|c|}{2020}} & -0.6 & -2.1 \\
\hline & & $(-0.2 ;-3.4)$ & $(-1.0 ;-3.9)$ \\
\hline \multirow{2}{*}{\multicolumn{2}{|c|}{2050}} & -1.1 & -2.4 \\
\hline & & $(-0.4 ;-6.4)$ & $(-0.9 ;-4.2)$ \\
\hline
\end{tabular}

Source: Authors' calculations.

Note: Medians of the country groups, minimum and maximum are given in brackets. 


\section{SUMMARY, POLICY CONCLUSIONS AND FUTURE RESEARCH}

As this study shows, the population share of those of working age in the economies under investigation will decrease for decades to come (Figure 2), while dependency rates will rise (Figure 3). We used an indicator, called pressure-to-space, to rank the fiscal pressure induced by demographic changes in relation to the labour market space. According to this measure, the pressure is mounting most in the developed economies (especially Poland, Czech Republic and Greece) while the majority of the developing economies rank at the bottom of the list. However, in some developing economies (notably Turkey and India) the pressure is mounting quickly. Moreover, we show that when old age costs per person are pitched at the level of Turkey, developing economies will even surpass some developed economies in the ranking list.

Methodologically the pressure-to-space indicator is tailored to identify how countries perform in comparison with their peers.From a macroeconomic policy point of view, the change in this indicator over the course of time is more relevant. Our panel data analyses shows a large explanatory power of $90 \%$ of the labour market space for the set of 50 countries during 2000 2020 with the inclusion of fixed country and time effects. This implies that idiosyncratic country and time effects explain the labour market space well. Moreover, in the cross-country sample the relationship between the change in pressure during 2010 and 2020 and the labour market space in 2008 is positive and significant. Countries facing increasing pressure have thus the option to use the available space at the labour market. One such instrument is the official retirement age. Increasing the retirement age from 65 to 70 reduces old age pressure by almost $30 \%$ in the developed economies, while labour market space at the same time increases by $10 \%$.

We found no evidence that countries already started reducing their labour market space in anticipation of the rising fiscal pressure in the near future. Our econometric analyses thus show no significant causality running from the projected rise in fiscal pressure of the old or of the young to the current labour market space, neither for the developing countriesnor for the group of developed economies. This implies that the projected demographic change has not (yet) triggered labour market reforms aimed at higher labour market participation.

Future research should also include migration, accumulated public debts and the net international investment position. Alongside reducing space, the immigration of young workers, a low public debt and a high net international investment position might help to limit the rise in the fiscal burden in the transition to ageing economies. 
References

Andersen, Torben M., 2006, The Scandinavian model - Prospects and challenges, International Tax and Public Finance, 15(1):45-66.

., 2008, Fiscal sustainability and demographics - should we save or work more; CEPR Discussion Paper 7044.

Bloom, David E. and David Canning, 2004, Global demographic change: Dimensions and economic significance, Proceedings, Federal Reserve Bank of Kansas City, issue August, 9-56. Rick Mansfield and Michael Moore, 2007, Demographic change, social security systems, and savings, Journal of Monetary Economics, 54(1):92-114.

and Roddy McKinnon, 2010, Social security and the challenge of demographic change, Program on the Global Demography of Ageing (PGDA), working paper no 61.

Börsch-Supan, Axel, Agar Brugiavini and EnricaCroda, 2008, The role of institutions in European patterns of work and retirement, DipartimentoScienzeEconomiche Working Paper 44.

Bovenberg , A.Lans., 2008, The life-course perspective and social policies: An overview of the issues, CESifo Economic Studies, 54(4): 593-641.

Brooks, Robin, 2000, What will happen to financial markets when the baby boomers retire?, International Monetary Fund Working Paper 00/18.

Bruni, Michele, 2011, China's new demographic challenge: From unlimited supply of labour to structural lack of labour supply. Labour market and demographic scenarios: 20082048, Materiali di Discussione 643, Center for the Analysis of Public Policy, University of Modena and Reggio, Italy.

Bryant, Ralph C. And Warwick J. McKibbin, 1998, Issues in modelling the global dimensions of demographic change, Brookings discussion papers in international economics no. 141.

Esping-Andersen, Gøsta, 1990, Three worlds of welfare capitalism, Cambridge: Polity Press\& Princeton University Press.

European Commission DG Economics and Financial Affairs, 2006, The Long-term sustainability of public finances in the European Union. European Economy 4.

G20, 2006, Demography and financial markets, Proceedings of a conference of the G20, eds. Christopher Kent, Anna Park and Daniel Rees.

Galor, Oded, 2010, The demographic transition: Causes and consequences, Brown University, US.

Groot, Loek and Marga Peeters, 2011, A global view on demographic pressure and labour market participation, MPRA 32057. 
Hagist, Christian and Berndt Raffelhüschen, 2011, Long-term effects of public pension reform in Norway - A generational accounting analysis, Research Center for Generational Contracts 49.

Heller, Peter S., Assessing a government's exposure to fiscal risk, John Hopkins University.

Horioka, Charles Yuji, 2010, Ageing and saving in Asia, Pacific Economic Review 15(1): 46-55.

Horton, Mark, Manmohan Kumar and Paolo Mauro, 2009, The state of public finances: A cross-country fiscal monitor, International Monetary Fund Staff position note SPN/09/21.

International Labour Office (ILO), 2010, Employment and labour market adjustments in G20 countries during 2007-09 and outlook for 2010: A statistical overview. Washington DC, US.

Jarret, Peter, 2011, Pension reforms in Poland and elsewhere: The view from Paris, Center for Social and Economic Research (CASE) Network studies \& analyses no 425, Warsaw, Poland.

Kent, Christopher, Anna Park and Daniel Rees(eds.), 2006, Demography and financial markets. G20 Proceedings of a conference held in Sydney, 23-25 July 2006.

Lee, Ronald, Sang-Hyop Lee and Andrew Mason, 2006, Charting the economic life cycle, NBER Working Paper Series 12379.

Ley, Eduardo, 2010, Fiscal (and external) sustainability, World Bank.

Mason, Andrew, Sang-Hyop Lee and Gerard Russo, 2006, Demography of ageing across Asia, in: Handbook of Asian Ageing, H. Yoon and J. Hendricks (eds.), Baywood Publishing, chapter 2.

Meier, Volker and Martin Werding, 2010, Ageing and the welfare state: Securing sustainability, CES-IFO Working Paper 2916.

Mohamed, Issam A.W., 2011, Challenges of formal social security systems in Sudan, MPRA paper 31611.

Peeters, Marga, 2011, Demographic pressure, excess labour supply and public-private sector employment in Egypt - Modelling labour supply to analyse the response of unemployment, public finances and welfare, MPRA paper 31101.

Pissarides, Christopher A., 1998, The impact of employment tax cuts on unemployment and wages: The role of unemployment benefits and tax structure, European Economic Review 42: 155-183.

Van der Veen, Robert and Loek Groot, 2006, Post-productivism and welfare states: A comparative analysis, British Journal of Political Science 36: 593-618. 